\title{
Noni leaf and black tea enhance bone regeneration in estrogen-deficient rats
}

\begin{abstract}
Objective: Black tea and Nonileaf are among the dietary compounds that can benefit patients with bone resorption disorders. Their bone regeneration effects and their mechanisms were studied in estrogen-deficient rats.

Methods: Noni leaves (three doses) and black tea water extracts were fed to ovariectomized rats for $4 \mathrm{mo}$, and their effects (analyzed via mechanical measurements, micro-computed tomography scan, and reverse transcriptase polymerase chain reaction mRNA) were compared with Remifemin (a commercial phytoestrogen product from black cohosh).

Results: The water extracts (dose-dependently for noni leaves) increased bone regeneration biomarker (runt-related transcription factor 2, bone morphogenetic protein 2, osteoprotegerin, estrogen receptor 1 [ESR1], collagen type I alpha 1A) expressions and reduced the inflammatory biomarkers (interleukin-6, tumor necrosis factor- $\alpha$, nuclear factor $[\mathrm{NF}]-\kappa \mathrm{B}$, and receptor activator of $\mathrm{NF}-\mathrm{\kappa B}$ ligand) mRNA expressions/levels in the rats. The extracts also improved bone physical and mechanical properties. The extracts demonstrated bone regeneration through improving bone size and structure, bone mechanical properties (strength and flexibility), and bone mineralization and density.

Conclusions: The catechin-rich extract favored bone regeneration and suppressed bone resorption. The mechanisms involved enhancing osteoblast generation and survival, inhibiting osteoclast growth and activities, suppressing inflammation, improving bone collagen synthesis and upregulating ESR1 expression to augment phytoestrogenic effects. Estrogen deficiency bone loss and all extracts studied (best effect from Morinda leaf at 300 $\mathrm{mg} / \mathrm{kg}$ body weight) mitigated the loss, indicating benefits for the aged and menopausal women.
\end{abstract}

Keyword: Morinda citrifolia leaves; Bone regeneration; Epicatechin; Scopoletin; Black tea; Remifemin 